\title{
Model of agricultural extension service system to accelerate technology adoption for vanilla smallholder
}

\author{
Suci Wulandari*, and I Ketut Ardana \\ Indonesia Center for Estate Crops Research and Development, Bogor, Indonesia
}

\begin{abstract}
Transfer of knowledge and technology is the critical aspect to increasing the performance of vanilla agribusiness. Various technologies to accelerate the increasing productivity and quality of vanilla have been introduced. However, adoption at the smallholder level is still not optimal. This study aims to formulate an extension service system to accelerate technology adoption at the farmer level. The analytical method used is MICMAC. Extension activities in household approach, farm school, and farm demonstration or demonstration plot greatly influence other agribusiness components. On the other hand, the availability of other agribusiness components affects extension activities. Extension for vanilla smallholders tends to be dominated by individuals with technical aspects as the focus of the subject matter. However, behavioural and institutional elements are not yet determinants of the sustainability of the learning process. An extension service system is an integrated approach that encourages the transfer of knowledge, information, and technology as a continuous learning process. Integrated extension service system for vanilla agribusiness development based on knowledge support service. It is supported by agribusiness support service, policy, market opportunities, and industry organization. Knowledge support service encourages the establishment of individual and smallholder organization capacity development.
\end{abstract}

\section{Introduction}

Vanilla is a plantation crop with high economic value, especially from the vanillin found in fruit, which can be used in the food, cosmetic, and aromatherapy industries $[1,2]$. Therefore, the world market of vanilla shows excellent prospects. The development of vanilla presents a huge opportunity. The prediction indicates that in 2018, the global vanilla market contributed USD 510 million and will reach around USD 735 million by 2026, with a growth of $4.7 \%$ per year [3]. The growth of vanilla demand is influenced by the shifting in the use of pure vanilla by global food and beverage companies since 2012 which followed by other companies.

\footnotetext{
* Corresponding author: suciwulandari@hotmail.com
} 
Vanilla development in Indonesia is spread over several areas such as North Sumatra, Lampung, West Java, East Java, Bali, West Nusa Tenggara, East Nusa Tenggara, North Sulawesi, Central Sulawesi, South Sulawesi, and Papua. The main actors in the development of vanilla are smallholder plantations (100\%). The area of vanilla development in 2017 is 10,040 , with a production of 1,534 tons [4].

Indonesia plays an essential role in the world vanilla market. In 2007 Indonesia was the leading producer, with production reaching 3,700 tons, and Madagascar is the second-largest producer, with a total production of 2,800 tonnes [5]. However, the situation is reversed. In 2019 , Madagascar was the largest vanilla producer globally, supplying nearly $70 \%$ or 1,500 tonnes per year. Indonesia's role in the global market experienced a very significant decline. This condition is related to declining vanilla quality due to various problems in the vanilla agribusiness system, which is significantly associated with adopting technology and institutional innovations at the farmer level.

Various technologies to accelerate the increasing productivity and quality of vanilla have been introduced. However, adoption at the farm level is still not optimal. The use of highyielding varieties and GAP application is still limited. Besides that, there is stagnation in the development of vanilla processing systems. Collectors and exporters mainly do vanilla processing. This condition affects the added value and competitiveness of Indonesian vanilla in the global market. The low adoption of technology is caused by the absence of an extension system that involves all stakeholders. Extension activities are still partial and with limited content.

Extension workers play a vital role in developing farmers' capacity, which ultimately determines the performance of agricultural development in Indonesia [6]. The extension functions with multiple aspects include commodity production and productivity, processing, marketing, sustainable development, and institutional development. On the other side, various stakeholders are involved in extension and advisory services [7]. Moreover, extension and advisory services also refer to different models based on agribusiness commodity characteristics. Hence, the study aims to formulate an integrated extension service system for vanilla agribusiness to improve smallholder capacities, interactions between stakeholders, technical, social, institutional innovations, and support systems.

\section{Methodology}

\subsection{Time and location}

The research activity was carried out in 2019 in Sukabumi Regency, West Java. Sukabumi Regency is one of the vanilla development centers in West Java.

\subsection{Data Collection and analysis}

The research was conducted through surveys and field observations. Data was collected through interviews using a questionnaire. The number of respondents was 24 vanilla farmers.

Data analysis used Matrice d'Impacts Croises-Multiplication (MICMAC) or CrossImpact Matrix Multiplication Applied to The Classification. MICMAC analysis involves developing a graph that classifies factors based on driving power and dependence power [8] The analysis stages consist of: the formation of a Structural Self-Interaction Matrix (SSIM), the creation of a Reachability Matrix (RM), the formation of a conical matrix and level partitioning, and the preparation of a digraph [9]. The assessment is carried out using a 0-3 scale where $0=$ no influence, $1=$ weak, $2=$ moderate influence, $3=$ strong influence, and $\mathrm{P}$ $=$ potential influence [10]. The analysis was carried out using MICMAC software. 
The analysis in this study used a Potential Direct Influence Graph that describes the relationship between components. This graph shows how the visualization of the relationship between components, including extension, can be seen.

\section{Results and discussion}

\subsection{Identification of vanilla agribusiness development issues at smallholder's level}

The development of vanilla is influenced by risks that affect the performance achieved [11]. Problems in the development of vanilla agribusiness consist of problems at the internal and external sides. Internal problems in the agribusiness system can be managed by value chain actors, while external problems are managed by other stakeholders [12]. Issues from the internal side consist of seed problems, climate disturbances, disease attacks, fertilizers and water availability, and technology adoption. Meanwhile, problems at the external side are related to input prices, vanilla prices, access to capital, availability of labor, availability of technology, access to technology, and marketing $[13,14,15]$.

Issues from the farm side are dominated by superior variety regarding availability, access to obtain, and seed certification. Respondents stated that the availability of superior seeds was a very high (41.67\%) and high (58.33\%) problem (Figure 1).

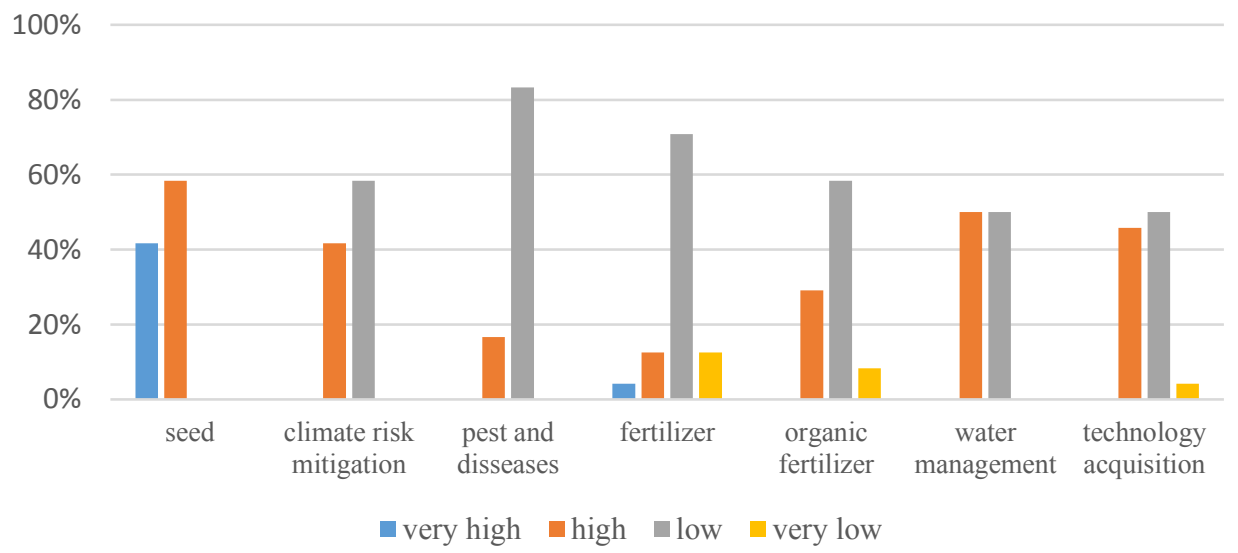

Fig. 1. Vanilla agribusiness development internal issues at the smallholder's level

The increase in vanilla productivity is achieved through the use of superior variety that has been released and propagated through seed source gardens built by the government. So far, only three vanilla varieties have been released by the Minister of Agriculture in 2008, namely Alor, Vania 1, and Vania 2.

The Vania 1 variety has the potential for wet pod production of $6.53-8.91$ tons/ha, dry pod production 1.83-2.56 tons/ha, and vanilla content of $2.8 \%$. The Vania 2 variety is moderately resistant to Vanilla Stem Rot ( $F$. oxysporum f.sp. vanilla) disease with wet pod production of 5.37-8.29 tons/ha, dry pod production 1.54-2, 19 tons/ha, and the yield of dry pods was 1.54-2.19 tons/ha, and vanilla content of 2.98\%. Meanwhile, the vanilla Alor variety is tolerant to Vanilla Stem Rot Disease resistance (F. oxysporum f. Sp. Vanilla). After six years, this variety has a production potential of 3.55-4.81 tons/ha/year and a vanillin content of $2.32-2.85 \%$. 
The vanilla seed source gardens that have been established consist of Alor and Nagakeo Regencies in East Nusa Tenggara, Sumedang Regency in West Java, Morotai Island Regency in North Maluku, Southeast Minahasa Regency in North Sulawesi, and Dairi Regency in North Sumatra.

These varieties have not been used optimally at the farmer level. Most of the farmers still use the seeds of local varieties that are not certified. This condition is allegedly also caused by the price of certified superior seeds, which are quite expensive. From the external side, the main problem is vanilla price fluctuations. Respondents stated that fluctuation is a very high (54.17\%) and a high (41.67\%) issue (Figure 2).

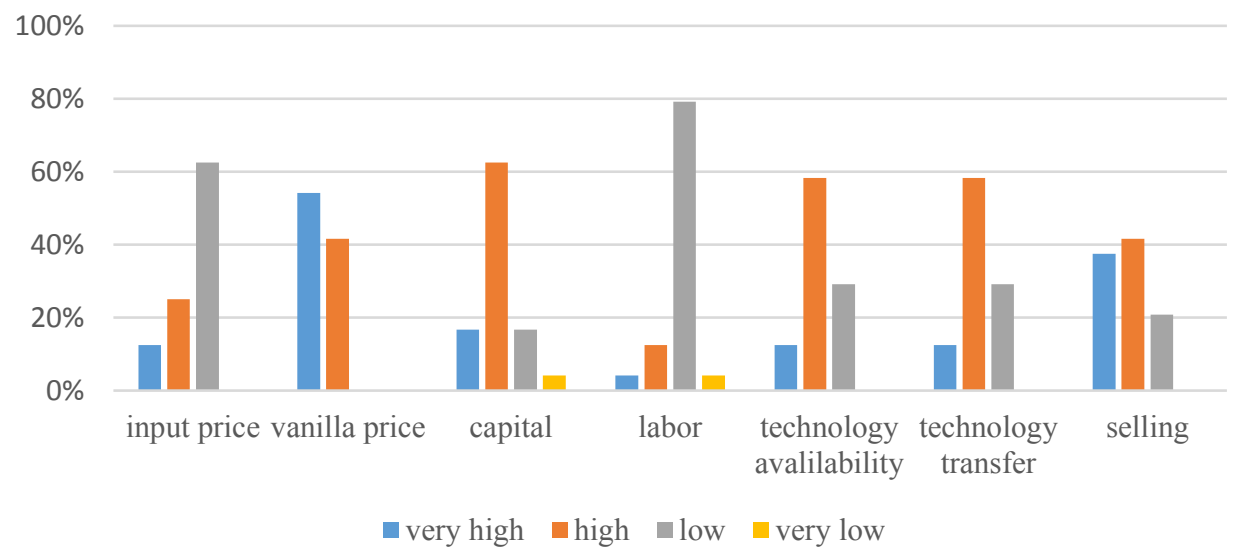

Fig. 2. Vanilla agribusiness development external issues

The diversification of vanilla products is still limited. Product trade in the form of primary products causes unstable prices. Vanilla products can be processed into powder, pod extract, and crystals, which can provide added value, but currently, the resulting product is still in the form of dried fruit.

The development of vanilla agribusiness is inseparable from the risks inherent in this agribusiness system. Perceptions of risk in production and investment behavior of farmers influence the development of vanilla plants in Indonesia [11]. Vanilla prices in the global market tend to fluctuate as a result of the supply and demand gap. In addition, the availability of artificial vanilla at a lower price encourages the use of pure vanilla to be limited.

From the supply side, climate disturbances affect vanilla production. Climate disturbances such as Enawo cyclone in Madagascar have destroyed a third of the country's vanilla crop. Given Madagascar's enormous contribution to the global market, this condition causes fluctuations in world vanilla prices. However, the opportunity to meet demand cannot be automatically fulfilled by other producing countries because after planting, it takes three years to move in the production period.

\subsection{Extension activities and vanilla smallholder' needs for extension activities}

The implementation of extension activities on vanilla cultivation and post-harvest is still very limited. Most of the respondents stated that they had never received an extension related to seeding $(87.50 \%)$, cultivation $(91.67 \%)$, pest and disease control $(87.50 \%)$, and post-harvest $(91.67 \%)$ (Figure 3). Therefore, information dissemination is dominated by exchanging information between farmers and through farmer groups. 


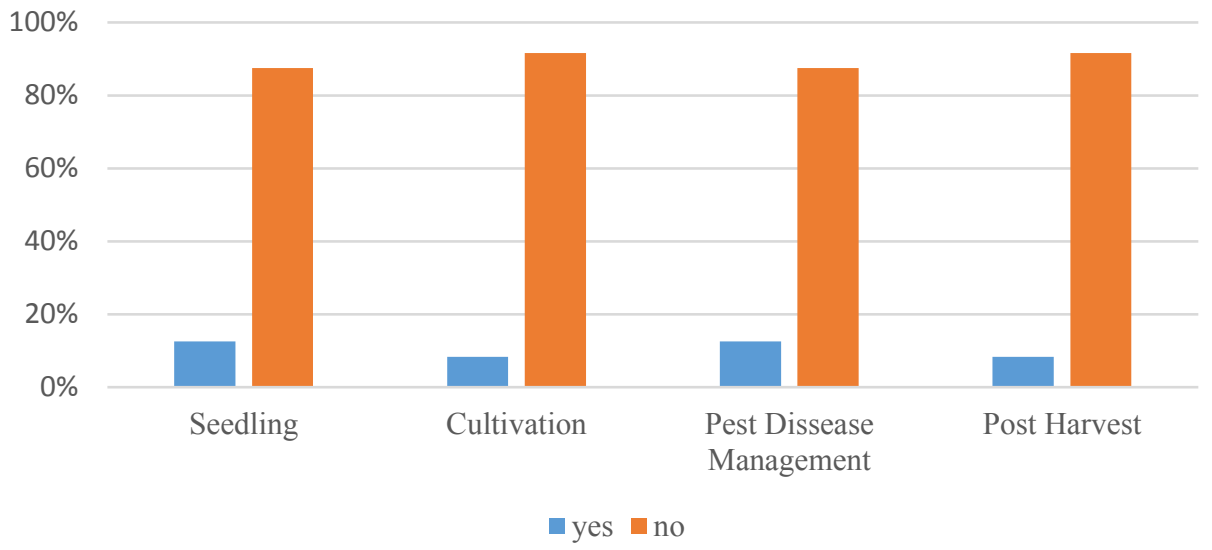

Fig. 3. Extension activities at vanilla smallholder's level

In terms of farmer needs, most farmers stated that they needed extension and assistance (91.67\%) (Figure 4). In addition, farmers need the provision of cultivation technology $(91.67 \%)$, provision of processing technology $(79.17 \%)$, provision of processing machinery and equipment $(62.50 \%)$, access to capital $(91.67 \%)$, provision of agricultural inputs (91.67\%), plot demonstration (75\%), main garden development (62.50\%), marketing assistance $(91.67 \%)$, and provision of agricultural insurance $(87.50 \%)$. The data shows that farmers not only need technology but also need other agricultural services, including extension. Technology adoption can run well if technology is available and farmers have access to technology transfer services through extension.

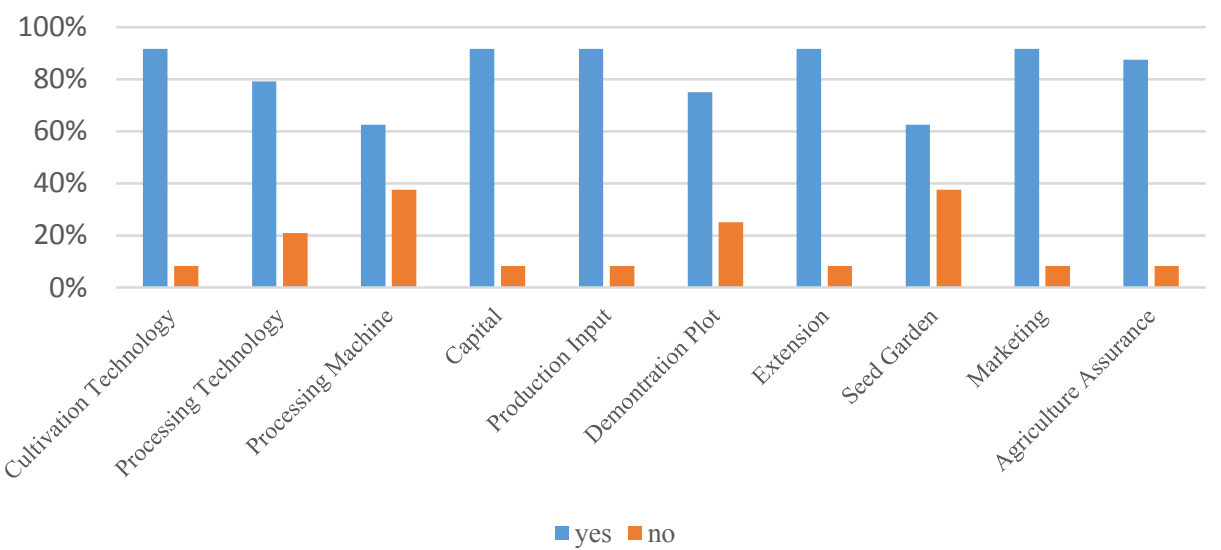

Fig. 4. Extension activities need from vanilla smallholder perception

\subsection{Agricultural extension service system for vanilla smallholders}

Based on the issues faced by vanilla farmers, it can be seen that the problems faced are not only in the technical aspect but also in the managerial and institutional aspects. Therefore, technical cultivation problems must be followed by improvements in harvest handling, postharvest, and processing to achieve optimal quality levels. In addition, it is necessary to 
strengthen farmer institutions to support seed propagation and product processing carried out in groups.

Extension is one component in agribusiness development, in addition to other components, namely seed gardens, agricultural production facilities, application of Good Agricultural Practices (GAP), Good Processing Practices (GPP), technology, capital, marketing strategies, and agricultural insurance. From the potential direct influence analysis (Figure 5), it can be seen that extension activities in the form of a household approach, farm school, and farm demonstration or demonstration plot have a significant influence on other agribusiness components. On the other hand, the availability of other agribusiness components affects extension activities. Therefore, an extension system for vanilla agribusiness is suggested to be designed as an integrated system (Figure 6).
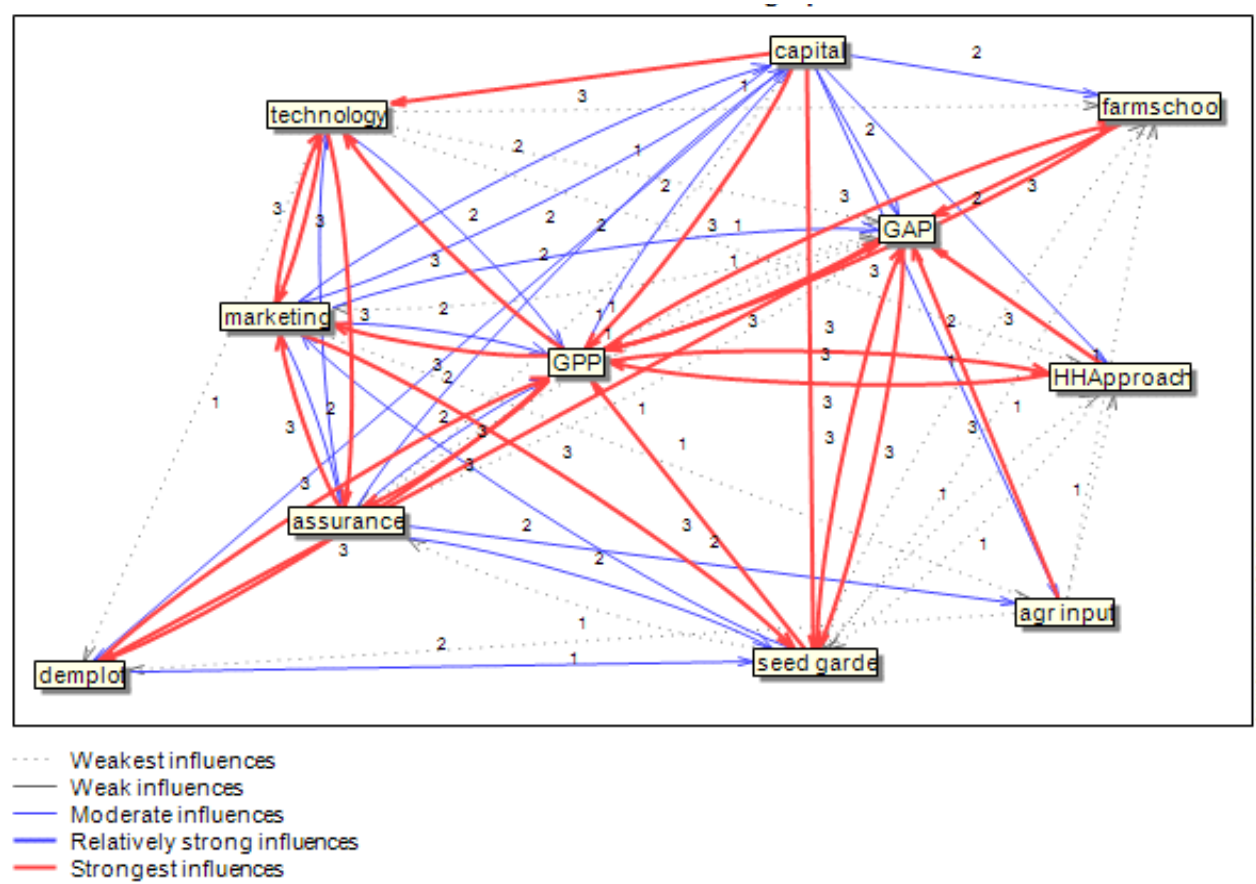

Fig. 5. Potential direct influence graph for vanilla agribusiness development components

An integrated extension system for vanilla agribusiness development is built based on knowledge support services that are supported by agribusiness support services, policies, market opportunities, and industrial organizations. The system is in line with the characteristics of smallholder farmers with limited access and resources, processing systems at the farmer level that are still traditional, and marketing that does not fully meet quality requirements.

Knowledge management has become a crucial factor for the viability and sustainable development of enterprises [16]. Knowledge Support Service encourages the establishment of individual and smallholder organization capacity development. Individual capacity development consists of knowledge transfer, information transfer, and technology transfer activities. Smallholder organization capacity development consists of bonding social capital in the form of internal strengthening of farmer organizations, bridging social capital to strengthen farmer organization networks, and linking in the form of connections between networks $[17,18]$. 


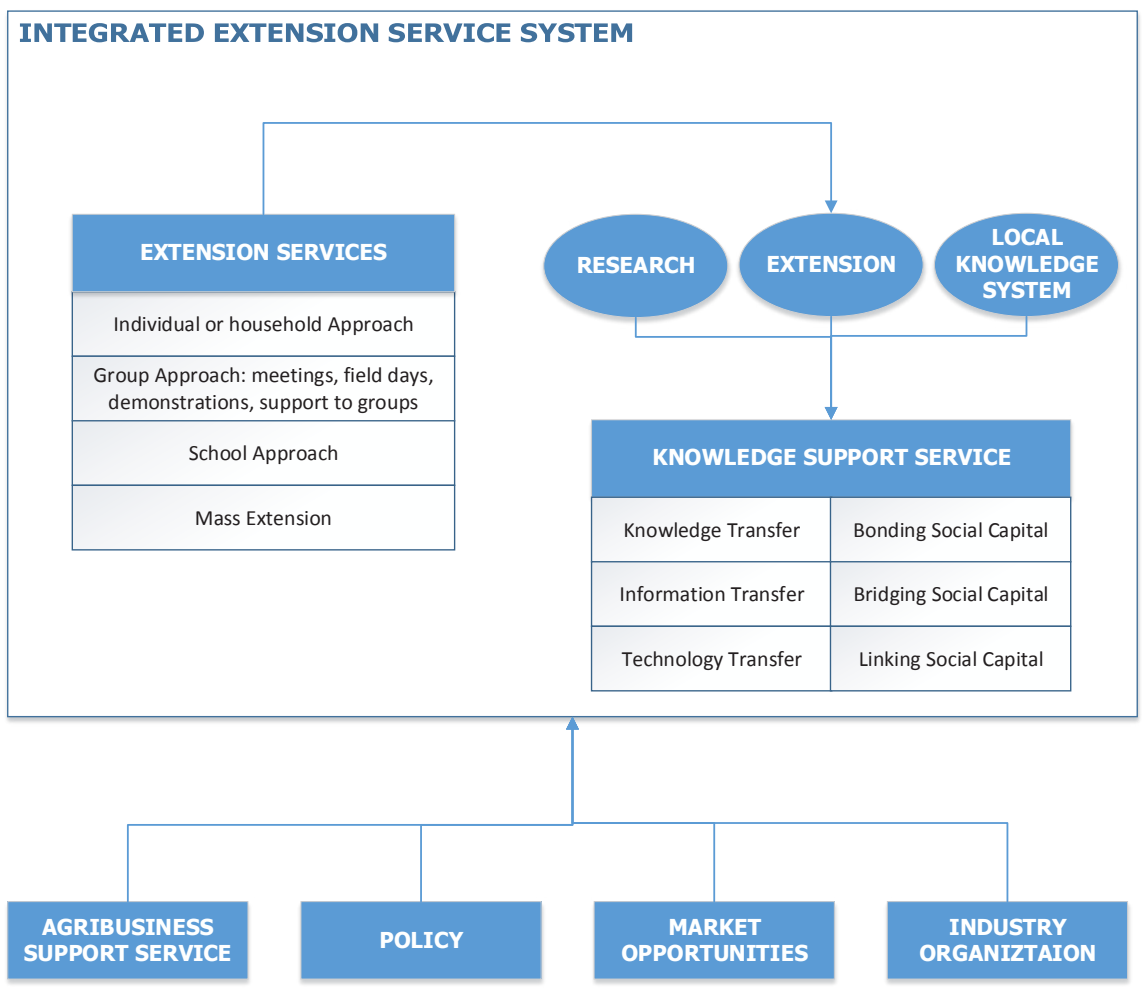

Fig. 6. Integrated extension service system for vanilla agribusiness development

Extension activities will be related to research activities carried out by research institutions and local knowledge systems at the farmer level. In addition, capacity building will be carried out through: (1) individual and household approach; (2) group approach: meetings, field days, demonstrations, support to groups; (3) school approach, and (4) mass extension. Because vanilla is an export commodity with high-quality requirements (19), a comprehensive and integrated extension system is needed. The integrated extension service system for vanilla agribusiness development is expected to increase farmers' knowledge and accelerate technology adoption through the support of research institutions and extension agencies. In addition, this system also encourages the strengthening of farmer organizations, considering that farmer groups carry out vanilla processing and marketing.

\section{Conclusion}

The development of vanilla agribusiness faces various challenges due to various issues, including knowledge and technology transfer. The conventional extension that a one-way communication and only focuses on technical matters will not significantly improve. The extension activities have a significant influence on other agribusiness components. Conversely, the availability of other agribusiness components affects extension activities. Therefore, an extension system for vanilla agribusiness is suggested to be designed as an integrated system.

The transformation at the farmer level aims to change farmers' skills and mindset to build a sustainable production system. The integrated extension system for vanilla agribusiness 
development is expected to encourage the implementation of GAP and processing that maintains quality, and build a sustainable market.

An integrated extension service system for vanilla agribusiness development is a model that integrates stakeholders; main and supporting activities; and various approaches to transfer knowledge, information, and technology into a system whose components are integrated. The system is designed based on knowledge support services. The extension service system is reinforced by agribusiness support services, policy, market opportunities, and industry organizations.

Extension activities will be related to research activities carried out by research institutions and local knowledge systems at the farmer level. In addition, knowledge support service encourages the establishment of individual and smallholder organization capacity development. Through the integrated extension service system, the performance of the production system in the vanilla agribusiness will increase through sustainable technology adoption.

\section{References}

1. Vijayalakshmi S, Disalva X, Srivastava C, Arun A. Res J Pharm Technol. 12(6):3068. (2019)

2. Singletary KW. Nutr Today. 55(4):186-96. (2020)

3. Zion market research. Vanilla Market Report [Internet]. Available from: https://www.zionmarketresearch.com/market-analysis/vanilla-market (2018)

4. Ditjen Perkebunan. Statistik Perkebunan 2019. 21 p. (2019)

5. FAO. FAOSTAT [Internet]. [cited 2020 Nov 3]. Available from: http://www.fao.org/faostat/en/\#country. (2020)

6. AA. Indones J Agric Res. 3(2):77-88. (2020)

7. Maulu S, Hasimuna OJ, Mutale B, Mphande J, Siankwilimba E. Enhancing the role of rural agricultural extension programs in poverty alleviation: A review. Cogent Food Agric [Internet]. 7(1):1886663. (2021)

8. Ahmad M, Tang XW, Qiu JN, Ahmad F. Appl Sci. 9(2). (2019)

9. Dewangan DK, Agrawal R, Sharma V. E Procedia - Soc Behav Sci [Internet]. 189:41632. (2015)

10. Arias M. Mediterr J Soc Sci MCSER Publ. 7(4):10. (2016)

11. Wulandari S. E3S Web Conf. 232:1-9. (2021)

12. Manik JR, Refiswal, Salsabila. Analysis of Factors Affecting The Performance of Agricultural Extension Agent in Langkat District. Proceeding on International Conference on Sustainable Agriculture and Natural Resources Management. 2(01) 8994. (2018)

13. Melo J de, Olarreaga M, Takacs W. Rev Dev Econ. 4(1):1-20. (2000)

14. Pokorná I, Smutka L. Agris On-line Pap Econ Informatics. 3(1):23-33. (2011)

15. Osterhoudt SR. Am Ethnol. 47(3):249-63. (2020)

16. Zecca F, Rastorgueva N. Qual - Access to Success. 18(159):97-104. (2017)

17. Cofré-Bravo G, Klerkx L, Engler A. J Rural Stud. 69(May):53-64. (2019)

18. Dahal GR, Adhikari KP. CAPRi Work Pap. (79):1-23. (2008)

19. Bremm ES, Ingenbleek P. Strategic marketing perspective on small-scale vanilla producer organizations in Mexico. Wageningen University. (2015). 